Periodica Polytechnica Architecture, 50(1), pp. 12-20, 2019

\title{
Best Value Procurement (BVP) in Norwegian Construction Projects
}

\author{
Glumur Orri Högnason, Paulos Wondimu²,2, Ola Lædre \\ ${ }_{1}$ Norwegian University of Science and Technology (NTNU), Department of Civil and Environmental Engineering, \\ 7491, Trondheim, Norway \\ 2 Norwegian Public Roads Administration (NPRA), 0667, Oslo, Norway \\ *Corresponding author, e-mail: g.o.hognason@gmail.com
}

Received: 15 July 2018, Accepted: 06 February 2019, Published online: 01 April 2019

\begin{abstract}
The traditional contractor selection method, based on lowest price, has resulted in conflict, low quality products and a waste of resources. The need for an alternative supplier selection method has resulted in Best Value Procurement (BVP). BVP seeks to increase project value by utilizing the expertise of the contractor, while reducing the client's management, direction and control. Currently, pilot projects in the Norwegian construction industry are testing the method. This paper addresses 1) how BVP is implemented in practice, 2) what the experiences with BVP are, and 3) how BVP should be performed in future projects. The research was carried out through a literature study and two Norwegian case studies. A building project and a medium-size infrastructure project in the Norwegian public sector were investigated through nine semi-structured, in-depth interviews and document studies. The findings show that the practical use of BVP is in accordance with the theoretical approach. Furthermore, the experiences with BVP are mainly positive. However, some challenges have been identified, such as the clients' and contractors' lack of knowledge and experience with the BVP method. This may reduce the potential project value. The conclusion is that BVP is an effective and promising method for contractor selection and project management. However, for the success of future projects using the method, clients and contractors may benefit from more knowledge and experience with BVP. This can be done by training and by being persistent in using BVP in future projects. This paper is a revised version of a paper that has been published in the proceedings of the Creative Construction Conference 2018.
\end{abstract}

\section{Keywords}

best value procurement (BVP), early contractor involvement, public procurement, project management, Norway

\section{Introduction}

Projects in the construction industry often suffer from cost and time overruns (Sullivan, 2010). Various reasons for this have been suggested in the literature, but a recurring factor is traditional project procurement methods in which contractors are contracted sequentially. This can lead to silo thinking and a lack of goal alignment between the client and the contractor. Several studies indicate that earlier contractor involvement can increase the project value and reduce the conflict level between the client and the contractor (Snippert et al., 2015; Wondimu et al., 2016a).

One of the methods that can be used for early contractor involvement is Best Value Procurement (BVP). BVP is a method for vendor selection and project management, which seeks to increase project value by emphasizing the competence and expertise of the vendor. The method utilizes previous performance information and interviews with key personnel to find the presumed best value vendor for the current project. The vendors compete based on project capability, their ability to identify risk, the additional value they can provide, interviews, and price (van de Rijt et al., 2016). The competition within these factors should lead to the selection of the vendor who offers the best value. BVP can be applied to procure all sorts of vendors, be that contractors for public works or service suppliers. This paper addresses how BVP is applied to construction projects, and in the following the word 'contractor' is used instead of the more general term 'vendor'.

Several different BVP methods exist, but this paper addresses the method that was developed by Dean Kashiwagi at Arizona State University in 1991 (Kashiwagi and Byfield, 2002). The method has been used with great success in the US (Kashiwagi, 2016). BVP was introduced to the European 
market in 2005 when pilot projects were implemented in the Netherlands (van de Rijt and Santema, 2012). The experiences with the method in the Netherlands have been promising, and the method is now being tested in Norway.

Despite the promising experiences in the US and Netherlands, several challenges have been identified with the method. For instance, the method is challenging to implement in the client's organization, and it demands thorough training of both the client and contractor (van de Rijt et al., 2016). Furthermore, the public procurement rules in EU and Norwegian law set certain limitations to the use of innovative procurement methods for public project owners (Krüger, 2004). Public project owners must adhere to the public procurement principles of competition, equal treatment, and non-discrimination. As a result, the original BVP method must be implemented in a modified form for public project owners in the EU (Leeuwen, 2011). In addition, there are some practical barriers to implementing such methods of early contractor involvement, such as traditional culture and contracting practice (Wondimu et al., 2016b).

Although several studies have been conducted on the use of BVP in the US and Netherlands, there is a knowledge gap on the use of BVP in other countries, including Norway. The purpose of this paper is therefore to study the introduction of BVP to the Norwegian construction market. By studying the practical use of BVP, and gathering experience data from the pilot projects, the knowledge database on how BVP can be implemented in the future may be strengthened. This paper addresses the following research questions:

- How was BVP implemented in practice?

- What are the experiences with BVP?

- How should BVP be performed in future projects?

This study is limited to two Norwegian cases that are medium-sized municipality projects. Furthermore, both cases are still in the execution phase. Therefore, the generalizability of the findings may have limitations.

\section{Method}

The research was carried out through a literature study and two case studies. The literature study was conducted in accordance with the recommendations given by Arksey and O’Malley (2005). Search words such as BVP, Best Value Procurement, Best Value, PIPS, EU and combinations of these were used. Citation chaining was used for important documents. The objective of the literature study was to develop a theoretical background on how BVP should be performed, and to gain insight in previous experiences with the method.

To address the research questions, two cases were studied according to the recommendations by Yin (2013). The case studies involved two medium-sized municipality projects in the Norwegian public sector: a building project and an infrastructure project. The main characteristics of the case projects are presented in Table 1 .

The cases were investigated through in-depth interviews with key personnel in the two projects, in addition to a losing bidder. A total of 9 interviews were conducted with interviewees from both the project owners' side and the contractors' side. As such, both the client's and the vendor's perspective have been examined. The roles of the interviewees are listed in Table 2.

The interviews were conducted in a semi-structured manner, with an underlying interview guide containing central questions. The interview guide helped to give consistency through the different interviews, and to increase the validity of the data. The interviews were held face-toface, which is generally regarded as beneficial for sharing information. The interviews lasted from one to one and a half hours. The interviews were recorded with permission from the interviewees. Transcriptions of the interviews were afterwards sent to the interviewees for approval to increase the reliability of the data.

Table 1 Main characteristics of the two cases

\begin{tabular}{|c|c|c|}
\hline Project name & Type and complexity & Cost (EUR) \\
\hline $\begin{array}{l}\text { Flatåshallen } \\
\text { Flatås sports } \\
\text { club }\end{array}$ & $\begin{array}{c}\text { Building project } \\
\text { Construction of a sports hall, } \\
\text { indoor football pitch, offices, } \\
\text { and canteen. Total size: Approx. } \\
6200 \mathrm{~m}^{2} \text {. Expected completion in } \\
\text { August/September } 2018 \text {. }\end{array}$ & 7200000 \\
\hline $\begin{array}{l}\text { Metrobuss } \\
\text { Trondheim } \\
\text { municipality }\end{array}$ & $\begin{array}{c}\text { Infrastructure project } \\
\text { Construction of a four-lane } \\
\text { highway, bicycle and walking } \\
\text { trails, and two metrobus stops. } \\
\text { Length: Approx. } 800 \text { m. Expected } \\
\text { completion in July } 2019 \text {. }\end{array}$ & 7700000 \\
\hline
\end{tabular}

Table 2 The roles of the interviewees

\begin{tabular}{ll}
\hline Project name & Role of interviewee (perspective) \\
\hline Flatåshallen & 1. Project leader (client) \\
Flatås sports club & 2. Project leader (contractor) \\
& 3. Member of grading group (client) \\
& 4. Member of grading group (client) \\
& 5. Losing bidder (contractor) \\
Metrobuss & 1. Project leader (client) \\
Trondheim municipality & 2. Project manager (client) \\
& 3. Project leader (contractor) \\
& 4. Member of grading group (client) \\
\hline
\end{tabular}


To supplement the data obtained through the interviews, document studies were also carried out. Access to project documents was given through project intranets. The documents included tender documents, contracts, and design plans.

\section{Theoretical framework: The BVP method}

BVP is based on a principle that the contractor is an expert and they should be allowed to evaluate the price and duration of a project based on the client's desired outcome of the project but not on the detailed specification. Also, it relies on the premise that the contractors deliver the best result when they become responsible for the execution of the project, and when they are required to identify, manage and minimize the technical risks (Apostol, 2011).

Although BVP is a detailed method for procurement and project management according to literature, it does not contain any set rules for how it should be implemented. Thus, there are various ways to apply the method. However, the main principles and philosophy of BVP must be applied for the method to work as proposed (Witteween and van de Rijt, 2013).

The main reference on how the theoretical model of BVP should be implemented is the book written by the originator of the method - Dean Kashiwagi (Kashiwagi, 2016). However, in the European context, van de Rijt and Santema's 'Prestatieinkoop' books are perhaps more important (van de Rijt and Santema, 2013; van de Rijt et al., 2016). This is because these books present the BVP method in an adapted form that seeks to fulfill EU public procurement legislation requirements. Different variants of this method is the approach that has been used in Dutch BVP projects. Since the Dutch approach is the method that the Norwegian projects are based on, it is also the approach that will be presented in this section.

\subsection{The principles of BVP}

The basic idea behind BVP is that the vendor - i.e. the contractor - is the expert on how the project should be executed. The control over the execution of the project should therefore to a larger extent be transferred to the contractor. Conversely, the client's management, direction, and control of the project should be minimized. This is done by shifting decision making towards the contractor (Kashiwagi, 2016).

Furthermore, the risks of the project are not transferred from the client to the contractor, but rather the management and control of these risks (van de Rijt et al., 2016).
A core principle of BVP is the use of past performance information to predict the performance of the contractor in the current project (van Duren and Dorée, 2010). As such, it is important that the previous performances of the contractor are measurable, and that they can be substantiated with controllable documentation. Past performance information is an important part of the selection process, but the contractor's performance in the current project is also measured in the execution (van de Rijt et al., 2016).

The main goal behind BVP is to increase the project value while shortening the procurement time and maintaining competition between contractors. The increase in project value means that the goals of the project should be fulfilled to the largest possible degree, while still minimizing the project costs (Kashiwagi, 2016).

Although the BVP method is based on the contractor's expertise, it is not necessarily based on a trust in the traditional sense of the word (Bos et al., 2015). The need for trust should be minimized through principles of transparency and accountability. In other words, the contractor's provision of performance information should lead to the client not having to trust the contractor, but rather become certain about the contractor's expertise. Snippert et al. (2015) denote this as a calculus-based trust, as opposed to traditional, relational trust. However, a traditional trust relationship between the client and the contractor will typically be developed in the Selection and Clarification phase.

\subsection{The four phases of BVP}

To understand the BVP method, it is necessary to have insight in how the phases of the method work. BVP is typically conducted in four phases: 1) Preparation (or Pre-qualification as it is called by Kashiwagi (2016)), 2) Selection, 3) Clarification, and 4) Execution. The phases are illustrated in Fig. 1.

The four phases consist of different core elements and activities that may be applied to standardize the BVP procedure. In the following, some of the core elements from theory (van de Rijt et al., 2016) and elements that have been identified in previous studies (Storteboom et al., 2017) will be presented.

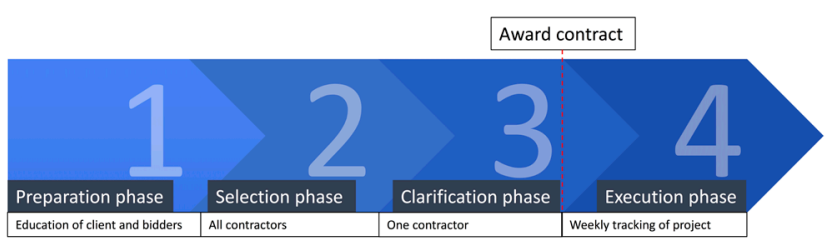

Fig. 1 The four phases of BVP, adapted from Kashiwagi (2016) 


\subsubsection{Preparation phase}

The Preparation phase is the first phase. In this phase, the client and the contractor are prepared for the process of using BVP by receiving education and training in the method.

The phase starts with the selection of a sponsor in the client's organization who is responsible for the BVP (van de Rijt et al., 2016). To gain training and insight in the BVP method, the involvement of an external BVP expert is usually beneficial. After that, a core team in the organization is selected and educated. The core team can for example consist of a project leader, a procurement leader, a representative from the management, and a person with competence in the type of project that is to be executed (van de Rijt et al., 2016). The use of pre-qualification - i.e., minimum legal and financial requirements for the contractors - may also be used. This is generally not recommended by van de Rijt et al. (2016), but it may be beneficial if there are many potential bidders.

Furthermore, a core document should be created. This contains information on the project scope, the project objectives, the weighting criteria, and the budget ceiling. The core document is to be released as information to the bidders (Kashiwagi, 2016). In public procurement, BVP contractors are typically selected by the criteria of $M E A T$ (Most Economically Advantageous Tender). Thus, other factors than price are evaluated. Since BVP uses an open budget with a ceiling - i.e., the client's maximum price is released as information to the contractors - the risk of procuring an expensive project is lowered. This yields room for weighting the criterion of price lower: Price is commonly weighted at around $25 \%$ in BVP projects (van de Rijt et al., 2016).

When the core document has been created, the process of inviting contractors for a tender competition can be started. Training sessions for the contractors may be held as part of the process of conducting the tender competition, for creating awareness about BVP in the market and educating the contractors.

\subsubsection{Selection phase}

The Selection phase is the second phase of BVP. The goal of this phase is to identify and select the best value contractor. The Selection phase is typically conducted in three steps (van de Rijt et al., 2016):

1. Evaluation of written documents from the contractors,

2. interviews with key personnel from the contractors, and
3. prioritization of the contractors according to the evaluation of the written documents, interviews, and price.

The phase starts with the contractors sending in their written offers, which consists of three documents: Project Capability, Risk Assessment and Value Added. In addition, the price is provided in a separate document. It is vital that the documents are short; no more than 2 pages each. This is an important part of maximizing the resource efficiency of the involved parties. Furthermore, the provision of dominant information is a key term: The information given in the written documents should be accurate, measurable and verifiable.

To evaluate the offers, a grading group is used. However, two or more independent grading groups may also be used to improve the objectivity of the evaluations. This was done in some of the Dutch projects at Rijkswaterstaat (Storteboom et al., 2017). The members of the grading group evaluate each document individually and set scores (van de Rijt et al., 2016). On the basis of the scores that have been given by the grading group, it is decided which of the contractors that go through to the interviews. Kashiwagi (2016) uses the term shortlisting about this step. Van de Rijt et al. (2016) do not recommend shortlisting, but rather advice that all the contractors should normally go through to the interviews.

It is important that the interviews are conducted with the contractor's key personnel who will actually do the work in the current project, such as project managers (van de Rijt et al., 2016). The interviews are recorded, transcribed and become part of the contract. The contractors are then graded and based on the weighting criteria the best value contractor is selected. A dominance check can then be performed, in which the accuracy of the information given by the contractor is assessed to ensure that the best value contractor has been selected (Kashiwagi, 2016).

\subsubsection{Clarification phase}

The Clarification phase is perhaps the most important phase (van de Rijt et al., 2016). In this phase, the selected contractor is given time to clarify and elaborate their offer. However, no negotiations or additions to the offer are to take place in this phase. Furthermore, no 'real work' is to be done in this phase: The Clarification is rather a phase for defining the project to the largest possible degree, such that all the main aspects of the project have been addressed before the execution starts. The idea behind this model is 
to save transaction costs because the other bidders do not need to use resources in detailing the project.

The Clarification phase should be led by the contractor. The presumption is that the contractor is the expert, and he should not be dictated or micromanaged by the client (Kashiwagi, 2016). This phase typically lasts 4 to 6 weeks (van de Rijt et al., 2016). If the client is convinced that the selected contractor is indeed the contractor that provides the best value for the current project, the contract is signed at the end of this phase.

The Clarification phase starts with a kick-off meeting. Here the contractor shall present his plans in detail to the client. A risk management plan should be formed, which describes all the risk factors in the projects and how they can be reduced. Furthermore, a scope document should be created, which describes which activities are part of the project and which activities that are not. To make the contractor's performance measurable, Key Performance Indicators (KPIs) should also be formed. These should be used to measure the contractor's performance in the Execution phase (van de Rijt et al., 2016).

If the project is complex and involves several subcontractors, elaboration of potential critical subcontractors may be requested (Storteboom et al., 2017). The contractor should also be involved in framing of the contract. However, this does not mean that the contractor writes the entire contract; but through interviews and statements made in the Clarification phase, the contractor will inevitably contribute to the content of the contract (Witteween and van de Rijt, 2013).

Reassessment of interviews may also be done to ensure that any concerns from these are addressed (Storteboom et al., 2017). It should also be made clear that the client is financially responsible for all uncontrollable risk (van de Rijt et al., 2016). This gives a larger incentive for the contractor to identify the risk factors that lie outside of his control, with accompanying plans on how to mitigate these risks. A risk contingency fund may be used to account for unforeseen circumstances and to incentivize the contractor to continue to work to minimize risks in the Execution phase. This is not part of the original BVP methodology but has been used in some Dutch projects (van de Rijt et al., 2011; Storteboom et al., 2017).

The Clarification phase ends with an award meeting. At this stage, all risk factors and scope of the project should be solved, and the KPIs should be agreed. If the contractor and client are in agreement, the contract may be signed.

\subsubsection{Execution phase}

The Execution phase is the final phase of BVP. In this phase, the project is to be executed in accordance with what the client and the contractor have agreed upon in the Clarification phase. Both Kashiwagi (2016) and van de Rijt et al. (2016) state that it is essential that both the client and the contractor stick to the BVP method in the Execution phase.

The weekly risk reporting is important in this phase, in which the contractor keeps the client updated on the status of the project. Both positive and negative deviations in relation to the project plan should be reported, in addition to any changes in risks. This is a key part of securing transparency and protecting the client from poor performances from the contractor (van de Rijt et al., 2016).

The contractor should also include performance measurements in accordance with the KPIs as part of the weekly risk reporting (van de Rijt et al., 2016).

A directors reporting may also be used. This is a report that is delivered to the client's management, such that the project's costs and time can be monitored (van de Rijt et al., 2016).

\section{Results and discussion}

In this section, the results from the two case studies will be presented and discussed. The projects are still in the Execution phase, and the results are limited to the experiences that have been made to this stage of the projects.

\subsection{The use of BVP in practice}

The use of BVP in the two Norwegian projects aligns with the theoretical approach identified in the literature. No major nonconformities to the theoretical model were discovered. A matrix of BVP elements and other elements that were identified in the literature is presented in Table 3, with indicators of the presence of such elements in the two cases.

Procurement was done using an open tender procedure. Both projects have opted for the use of underlying standard design-build contract provisions, namely the Norwegian standard NS 8407.

In both projects, all four phases have been used. Prequalification was not used in either of the projects. This was not deemed necessary as the clients anticipated a fairly low number of bidders. Furthermore, shortlisting was not used, such that all the bidders were given the opportunity to be interviewed. Two or more independent grading groups were not used. Elaboration of potential 
Table 3 Presence of BVP elements in the two cases

\begin{tabular}{|c|c|c|}
\hline Elements from BVP & $\begin{array}{l}\text { Flatås- } \\
\text { hallen }\end{array}$ & $\begin{array}{c}\text { Metro- } \\
\text { buss }\end{array}$ \\
\hline \multicolumn{3}{|l|}{ 1. Preparation phase } \\
\hline Sponsor & $\mathrm{X}$ & $\mathrm{X}$ \\
\hline Involvement of external BVP expert & $\mathrm{X}$ & $\mathrm{X}$ \\
\hline Selection and education of core team & $\mathrm{X}$ & $\mathrm{X}$ \\
\hline Pre-qualification of contractors & - & - \\
\hline Use of all four phases & $\mathrm{X}$ & $\mathrm{X}$ \\
\hline Training sessions for contractors & $\mathrm{X}$ & $\mathrm{X}$ \\
\hline Core document & $\mathrm{X}$ & $\mathrm{X}$ \\
\hline Open budget w/ceiling & $\mathrm{X}$ & $\mathrm{X}$ \\
\hline \multicolumn{3}{|l|}{ 2. Selection phase } \\
\hline $\begin{array}{l}\text { Award criteria in MEAT: } \\
\text { Project capability } \\
\text { Risk assessment } \\
\text { Value added } \\
\text { Interviews } \\
\text { Price }\end{array}$ & $\begin{array}{l}25 \% \\
15 \% \\
10 \% \\
25 \% \\
25 \%\end{array}$ & $\begin{array}{l}20 \% \\
20 \% \\
15 \% \\
25 \% \\
20 \%\end{array}$ \\
\hline Short listing & - & - \\
\hline Two or more independent grading groups & - & - \\
\hline Dominance check & $\mathrm{X}$ & $\mathrm{X}$ \\
\hline \multicolumn{3}{|l|}{ 3. Clarification phase } \\
\hline Kick-off meeting & $\mathrm{X}$ & $\mathrm{X}$ \\
\hline Risk management plan & $\mathrm{X}$ & $\mathrm{X}$ \\
\hline Scope document & $\mathrm{X}$ & $\mathrm{X}$ \\
\hline Elaboration of potential critical subcontractors & $\mathrm{X}$ & - \\
\hline Reassessment of interviews & $\mathrm{X}$ & $\mathrm{X}$ \\
\hline Key Performance Indicators (KPIs) & $X$ & $X$ \\
\hline Award meeting & $\mathrm{X}$ & $\mathrm{X}$ \\
\hline Contractor involved in framing of contract & $\mathrm{X}$ & $\mathrm{X}$ \\
\hline Owner responsible for all uncontrollable risk & $\mathrm{X}$ & $\mathrm{X}$ \\
\hline Risk contingency fund & - & $\mathrm{X}$ \\
\hline \multicolumn{3}{|l|}{ 4. Execution phase } \\
\hline Weekly risk reporting & $\mathrm{X}$ & $\mathrm{X}$ \\
\hline Performance measurements & $\mathrm{X}$ & $\mathrm{X}$ \\
\hline Directors reporting & - & $\mathrm{X}$ \\
\hline
\end{tabular}

critical subcontractors was requested in the Flatåshallen project. This was not necessary in the Metrobuss project, as there are few subcontractors in this project. A risk contingency fund was not used in the Flatåshallen project, due to a small margin in the project budget. Directors reporting was not used in the Flatåshallen project, as the project owner is a one-time construction client.

\subsection{The experiences with BVP}

The general view of BVP is positive in both projects. The clients and the contractors were mainly positive about the
Table 4 The experiences with BVP

\begin{tabular}{|c|c|}
\hline \multirow[t]{5}{*}{$\begin{array}{l}\text { Positive } \\
\text { experiences }\end{array}$} & $\begin{array}{l}\text { Project cost predictability because of the open budget } \\
\text { with ceiling }\end{array}$ \\
\hline & Faster procurement phase for the client \\
\hline & $\begin{array}{l}\text { The interviews are well suited to differentiate } \\
\text { between the contractors }\end{array}$ \\
\hline & $\begin{array}{l}\text { Contractors are to a larger extent evaluated on their } \\
\text { competence compared to traditional procurement } \\
\text { methods }\end{array}$ \\
\hline & $\begin{array}{l}\text { The Clarification phase provides foreseeability for } \\
\text { the execution }\end{array}$ \\
\hline \multirow[t]{5}{*}{ Challenges } & $\begin{array}{l}\text { The clients and contractors are uncertain about the } \\
\text { method }\end{array}$ \\
\hline & $\begin{array}{l}\text { Uncertain whether time or costs have been saved in } \\
\text { the procurement phase for the contractors }\end{array}$ \\
\hline & Legal challenges concerning public procurement law \\
\hline & $\begin{array}{l}\text { Difficult to balance the line between clarification and } \\
\text { negotiation in the Clarification phase }\end{array}$ \\
\hline & $\begin{array}{l}\text { Lack of specific contract provisions represents a } \\
\text { challenge in the Execution phase }\end{array}$ \\
\hline
\end{tabular}

BVP method and philosophy. However, some challenges have been identified. The positive experiences and challenges are presented in Table 4.

\subsubsection{Positive experiences}

In both projects, project cost predictability because of the open budget with ceiling was put forth as a positive element, especially from the clients' point of view. Since the budget with ceiling is released up front to the contractors, the probable cost of the project is known at an early stage.

Furthermore, the clients pointed to a faster procurement phase since the tender documents need less detailed descriptions.

The clients also agreed that the interviews were well suited to differentiate between the contractors. There was a great difference in how the contractors performed on the interviews, and the clients were very positive to using interviews as a means of differentiating between the contractors.

In addition, the contractors are to a larger extent evaluated on their competence compared to traditional procurement methods. The contractors express that this is a much-appreciated change to the usual tough price competition, which yields less room for their expertise.

Another positive experience is that the Clarification phase provides foreseeability for the execution. The contractor gets to know the project better through this phase, and relationships to the clients are formed. 


\subsubsection{Challenges}

Despite the many positive experiences with the use of BVP, there are some challenges.

The main challenge was that the clients and contractors are uncertain about the method. For example, many of the offers from the contractors lacked the specificity and verifiability that is expected in the BVP method. Furthermore, the contractors performed poorly on the interviews in general. The uncertainty with the method was also challenging in the Clarification phase: The contractors had trouble leading this phase, and they had trouble forming measurable KPIs. These challenges are probably caused by the contractors' lack of knowledge and experience with the method. Conversely, the contractors in both projects find that the clients are having trouble 'letting go' of control in the Clarification and Execution phase. This corresponds to the observations made by Snippert et al. (2015), in that clients frequently fall back on the traditional model of management, direction, and control, instead of leaving the technical decision making to the vendor. Thus, despite the presence of BVP elements in the two cases, there is a gap between theoretical and practical application of the BVP philosophy.

Furthermore, it is uncertain whether time or costs have been saved in the procurement phase for the contractors. Both contractors state that no costs or time has been saved in the procurement phase. Although BVP simplifies the procurement phase in that the contractors should only deliver 6 pages of documents, the price of the offer must still be calculated as usual, and the budget ceiling must be controlled. The contractors stated that they need to feel confident that their price is correct.

There are also some legal challenges concerning public procurement law. An interviewee expressed that it is challenging to subsequently reject a contractor who has been selected to the Clarification phase. At this stage, the contractor has put down a great deal of work and resources in the project and would probably not give up without a fight. As such, a proper rejection in accordance with EU public procurement law would require thorough documentation from this phase.

Both the clients and contractors stated that it is diffcult to balance the line between clarification and negotiation in the Clarification phase. Although there should be no negotiation in this phase, the distinction is not always easy to draw. This is a challenge that also has a side to EU public procurement law. There is a ban on negotiations in public tender competitions in the EU, and public clients may not negotiate with the bidders in an open or restricted procedure (European Communities, 1994). Public project owners must therefore be particularly careful to avoid negotiations in the Clarification phase.

In addition, the lack of specific contract provisions for BVP projects represents a challenge in the Execution phase. Both projects use underlying standard contracts. These do not account for any special considerations that must be taken when using the BVP method, such as the weekly risk reporting. For example, the standard contracts contain clauses that require the contractor to notify the client without undue delay if a change occurs. Thus, a challenge occurred when a change was reported in the weekly risk report, but not through the traditional change order system. This resulted in ambiguity about whether the change had been notified in time. The notification rules in the standard contracts are preclusive, such that failure to notify in time results in a loss of the right to claim monetary compensation or extension in time limits. Since accountability and transparency are important principles in BVP, a need for clarification of the Execution phase through contract terms has thus been identified.

\subsection{How should BVP be performed in future projects?}

The interviewees were asked about success factors and pitfalls with the method to develop suggestions on how BVP should be performed in future projects. In addition, the interviewees were queried on what could have been done differently in the current and future projects.

The interviewees agreed that the theoretical approach should be followed in future BVP projects. This is in accordance with the recommendations of van de Rijt et al. (2016).

An overview of some key success factors and pitfalls that were found is presented in Table 5 .

Table 5 Success factors and pitfalls of BVP

\begin{tabular}{ll}
\hline $\begin{array}{l}\text { Success } \\
\text { factors }\end{array}$ & $\begin{array}{l}\text { Education in the BVP method for both the client and the } \\
\text { contractor }\end{array}$ \\
& Using an external BVP expert with thorough BVP \\
knowledge and experience & \\
& Ability for the client to let go of control \\
& Appropriate budget ceiling and time plan \\
& Starting the BVP at an early enough stage of the project \\
\hline Pitfalls & $\begin{array}{l}\text { Considering the method too easy } \\
\text { Using BVP for the wrong kind of project }\end{array}$ \\
& $\begin{array}{l}\text { Not being able to differentiate between the best seller and } \\
\text { the best contractor in the Selection phase }\end{array}$ \\
& $\begin{array}{l}\text { Potential legal pitfalls with regards to public procurement } \\
\text { legislation if the method is not followed }\end{array}$
\end{tabular}




\subsubsection{Success factors}

The predominant success factor that was identified was an education in the BVP method for both the client and the contractor. This was put forth as a vital factor for succeeding with the BVP method and to creating ownership to the methodology. In this regard, the interviewees from the Metrobuss project also expressed that the internal training sessions on BVP should have been held earlier. The need for training in the Clarification and Execution phase is especially prevalent.

Using an external BVP expert with thorough BVP knowledge and experience was also put forth as a success factor, especially by interviewees from the client's side. This was argued as important to implement the method correctly so that the method can work as proposed and legal problems are avoided. The clients expressed that the need for external expertise is particularly prevalent in the first BVP projects that are implemented in the client's organization.

Ability for the client to let go of control was also mentioned as a success factor. The client must be prepared to provide more information than usual and focus on facilitating an environment where the contractor can succeed. This has been identified as a common challenge in previous BVP projects (Snippert et al., 2015; van de Rijt et al., 2016).

Furthermore, the contractors emphasize that an appropriate budget ceiling and time plan is important. If these are set too low, there will be a constant race against the clock and to keep cost margins low. This may result in suboptimal construction solutions and a heightened conflict level between the client and contractor, since cost will be a continuous issue throughout the project.

Starting the BVP at an early enough stage was stated as a success factor by interviewees from one of the contractors. To gain the benefits of the contractor's expertise, the contractors should be selected at a stage where they can exert real influence on the project. In the Flatåshallen project, applications for government permissions had been sent before the contractor was selected. As part of the applications, some main characteristics of the buildings were determined, such as building height. Although this saved some time for the client, since the processing of the applications could be done parallel to the procurement, the contractor expressed that this deprived them of freedom for how the project should be solved. The contractor pointed out that they are well known with the importance of creating a room of maneuver when obtaining building permissions from the government. Thus, an informant stated that a better solution would be to involve the contractor at a stage of the project where they could prepare the government applications.

\subsubsection{Pitfalls}

Considering the method too easy was regarded as a pitfall by both the clients and contractors in the two cases. Although BVP focuses on the expertise of the contractor, it still demands thorough education and cannot be regarded as simply a 'procurement trick'. In this regard, it is worth noting that van de Rijt et al. (2016) clearly state that a successful implementation of BVP requires a good understanding of the BVP philosophy and method.

Using BVP for the wrong kind of project was also identified as a potential pitfall by the interviewees. If the method is used for projects where there is little freedom in choice of solution, the expertise of the contractor cannot be fully utilized. The contractors warned against using BVP for simple and straight-forward projects, but rather advised that an ordinary design-build contract should be used in these cases.

Not being able to differentiate between the best contractor and the best seller in the Selection phase was also mentioned by several interviewees. It is important to stick to the dominant information that is provided in the written documents and the interview to avoid this pitfall.

Furthermore, an interviewee expressed that there are potential legal pitfalls with regard to public procurement legislation if the method is not followed. These pitfalls are related to the negotiation ban in open tender procedures, and the previously mentioned challenges that occur if the client wishes to reject a contractor in the Clarification phase and choose the second-best contractor.

\section{Conclusion}

This paper has addressed the use of Best Value Procurement (BVP) in two Norwegian construction projects. The study investigated how BVP was implemented in practice, what the experiences with BVP are, and how BVP should be performed in future projects.

The findings from the two cases indicate that BVP to a large extent has been implemented in accordance with the theoretical approach. Some minor deviations from the theoretical model have been identified, but these are related to BVP elements that are regarded as optional.

The clients' and contractors' experiences with BVP are mainly positive. The results indicate that the clients can make a faster call for tenders, the Clarification phase provides foreseeability for the execution, and the release of a maximum tender price to the bidders yields project cost predictability. At the same time, the contractors find that they can utilize their expertise to a larger degree. 
However, some challenges were identified during the practice of the method. First, both the contractors and the clients were inexperienced with the method. The contractors' tender offers lacked the specificity, measurability and verifiability that is expected in BVP, and the clients had trouble letting go of control. The Clarification phase was also characterized by traditional thinking. Secondly, it is uncertain whether time or costs have been saved for the contractors in the procurement phase, despite the theory on BVP suggesting a more efficient procurement phase. Thirdly, the legislation on public procurement represented a challenge, and the ban on negotiations in tender competitions is demanding to maintain in the Clarification phase. Lastly, the lack of specific contract provisions for BVP was challenging in the Execution phase.

\section{References}

Apostol, R. (2011) "Legal Perspective: Is Best Value Procurement achievable within the framework of the ARW 2005?", Journal for the Advancement of Performance Information \& Value, 3(1), pp. 72-89.

Arksey, H., O’Malley, L. (2005) "Scoping studies: towards a methodological framework", International Journal of Social Research Methodology, 8(1), pp. 19-32. https://doi.org/10.1080/1364557032000119616

Bos, A., Kashiwagi, D., Kashiwagi, I. (2015) "Changes Required to Sustain a Best Value Environment", Journal for the Advancement of Performance Information and Value, 7(1), pp. 1-16.

Duren, J. van, Dorée, A. (2010) "An evaluation of the performance information procurement system (PiPS)", Journal of Public Procurement, 10(2), pp. 187-210. https://doi.org/10.1108/JOPP-10-02-2010-B002

European Communities (1994) Official Journal of the European Communities No. L 111/114, 30 April 1994.

Kashiwagi, D., Byfield, R. E. (2002) "Selecting the best contractor to get performance: On time, on budget, meeting quality expectations", Journal of Facilities Management, 1(2), pp. 103-116. https://doi.org/10.1108/14725960310807872

Kashiwagi, D. (2016) "Best Value Approach", Kashiwagi Solution Model (KSM), Mesa, Arizona, USA.

Krüger, K. (2004) "Ban-on-negotiations in tender procedures: undermining best value for money?", Journal of Public Procurement, 4(3), pp. 397-436. https://doi.org/10.1108/JOPP-04-03-2004-B004

Leeuwen, M. van (2011) "Using Best Value Procurement in Europe, Need for Compromise?", Journal for the Advancement of Performance Information \& Value, 3(1), pp. 56-71.

Rijt, J. van de, Witteween, W., Vis, C., Santema, S. C. (2011) "Best Value at the Directorate-General for Public Works and Water Management in The Netherlands: A Case Study of the Procurement of Infrastructure Projects Worth \$1,200M", Journal for Advancement of Performance Information and Value, 3(1), pp. 90-100.

Rijt, J. van de, Santema, S. C. (2012) "The Best Value Approach in the Netherlands: a reflection on past, present, and future", Journal for the Advancement of Performance Information and Value, 4(2), pp. 147-160.
The results indicate that BVP is an effective and promising method for contractor selection and project management. For future projects, it is recommended that the theoretical approach to BVP should be followed. However, future clients and contractors may benefit from more knowledge and experience with BVP. This may be done by facilitating training sessions for the clients and contractors or by being persistent in using BVP in future projects. Through using BVP in future projects, both the clients and contractors will gain experience with the method.

Final conclusions can only be drawn after the projects have been finished, i.e. late 2018 and mid 2019 respectively.

Rijt, J. van de, Santema, S. C. (2013) "Prestatieinkoop - Met best value naar successvolle projecten" (Performance Procurement - With Best Value for Successful Projects), 3rd ed., Graphicom International, Pijnacker. (in Dutch)

Rijt, J. van de, Santema, S. C., Soilammi, A. (2016) "Best Value Procurement - Prestasjonsinnkjøp" (Best Value Procurement Performance Procurement), Rådgivende Ingeniørers Forening, Oslo. (in Norwegian)

Snippert, T., Witteween, W., Boes, H., Voordijk, H. (2015) "Barriers to realizing a stewardship relation between client and vendor: the Best Value approach", Construction Management and Economics, 33(7), pp. 569-586. https://doi.org/10.1080/01446193.2015.1078902

Storteboom, A., Wondimu, P., Lohne, J., Lædre, O. (2017) "Best Value Procurement - The Practical Approach in the Netherlands", Procedia Computer Science, 121, pp. 398-406. https://doi.org/10.1016/j.procs.2017.11.054

Sullivan, K. T. (2011) "Quality Management Programs in the Construction Industry: Best Value Compared with Other Methodologies", Journal of Management in Engineering, 27(4), pp. 210-219. https://doi.org/10.1061/(ASCE)ME.1943-5479.0000054

Witteween, W., van de Rijt, J. (2013) "Possible Barriers to a Successful Further Diffusion of the Best Value Approach in the Netherlands: Observations of Major Misunderstandings on the Concept and Theory", Journal for the Advancement of Performance Information and Value, 5(2), pp. 79-88.

Wondimu, P. A., Hosseini, A., Lohne, J., Hailemichael, E., Lædre, O. (2016a) "Early Contractor Involvement in Public Infrastructure Projects", In: Proceedings of the $24^{\text {th }}$ Annual Conference of the Int'l. Group for Lean Construction, Boston, MA, USA, pp. 13-22.

Wondimu, P. A., Hailemichael, E., Hosseini, A., Lohne, J., Torp, O., Lædre, O. (2016b) "Success factors for early contractor involvement (ECI) in public infrastructure projects", Energy Procedia, 96, pp. $845-854$. https://doi.org/10.1016/j.egypro.2016.09.146

Yin, R. K. (2013) "Case Study Research: Design and Methods", 5th ed., Sage Publications, Thousand Oaks, CA, USA. 